\title{
Cytokine Overproduction, T-Cell Activation, and Defective T-Regulatory Functions Promote Nephritis in Systemic Lupus Erythematosus
}

\author{
Marco Tucci, Stefania Stucci, Sabino Strippoli, and Francesco Silvestris \\ DIMO, Department of Internal Medicine and Clinical Oncology, University of Bari, Piazza Giulio Cesare 11, 70124 Bari, Italy
}

Correspondence should be addressed to Marco Tucci, m.tucci@dimo.uniba.it

Received 5 February 2010; Accepted 15 March 2010

Academic Editor: Brian Poole

Copyright ( $) 2010$ Marco Tucci et al. This is an open access article distributed under the Creative Commons Attribution License, which permits unrestricted use, distribution, and reproduction in any medium, provided the original work is properly cited.

\begin{abstract}
Lupus nephritis (LN) occurs in more than one-third of patients with systemic lupus erythematosus. Its pathogenesis is mostly attributable to the glomerular deposition of immune complexes and overproduction of T helper- (Th-) 1 cytokines. In this context, the high glomerular expression of IL-12 and IL-18 exerts a major pathogenetic role. These cytokines are locally produced by both macrophages and dendritic cells (DCs) which attract other inflammatory cells leading to maintenance of the kidney inflammation. However, other populations including T-cells and B-cells are integral for the development and worsening of renal damage. T-cells include many pathogenetic subsets, and the activation of Th-17 in keeping with defective T-regulatory (Treg) cell function regards as further event contributing to the glomerular damage. These populations also activate B-cells to produce nephritogenic autoantibodies. Thus, LN includes a complex pathogenetic mechanism that involves different players and the evaluation of their activity may provide an effective tool for monitoring the onset of the disease.
\end{abstract}

\section{Introduction}

Lupus nephritis (LN) is a major clinical manifestation of systemic lupus erythematosus that occurs in $15 \%$ of patients at diagnosis and in approximately $40 \%$ during the course of the disease. Renal biopsy is the gold standard for the diagnosis and follow-up, whereas the measurement of proteinuria identifies patients with overt renal failure, but fails to detect early silent disease. Thus, a better definition of the pathogenetic mechanisms leading to $\mathrm{LN}$ is required to identify effective markers of renal inflammation.

$\mathrm{LN}$ is generally attributed to an intriguing interplay between renal parenchymal cells and inflammatory cells recruited in consequence of the deposition and/or in situ production of immune complexes (ICs) [1]. ICs increase the production of cytokines, chemokines, and adhesion molecules which allow the progressive infiltration of macrophages, dendritic cells (DCs) and T-cells resulting in chronic renal failure [2]. Moreover, cytokines and chemokines secreted by cells infiltrating glomeruli further promote the migration of other inflammatory cells that are attracted toward the inflammatory sites in response to a concentration gradient $[3,4]$.

Notwithstanding SLE is considered a T helper- (Th-) 2 driven disease [5-7], experimental models of LN proved the primary role of Th1 cytokines for its development and severity, since large amounts of both interleukin- (IL-) 12 and IL18 have been found within glomeruli of humans as well as in murine models of glomerulonephritis [8-11]. In parallel, high amounts of Th2 cytokines as IL- 6 and IL-10 were found in sera of SLE patients with active disease, although they were not clearly associated with renal damage [12].

Macrophages and DCs are major producers of cytokines within glomeruli and their interaction with resident $\mathrm{T}$ cells amplifies the renal inflammation. In this context, the impaired T-cell activation as altered function of DCs has been demonstrated in SLE, whereas DCs activate naïve Tcells and regulate the cytokine production, and the T-cell polarization [13]. It has been recently described as a defect of circulating DCs in parallel with their increased migration toward the kidney due to attractive stimuli promoted by glomerular IL-18, IL-1, and chemerin [14]. Thus, while 


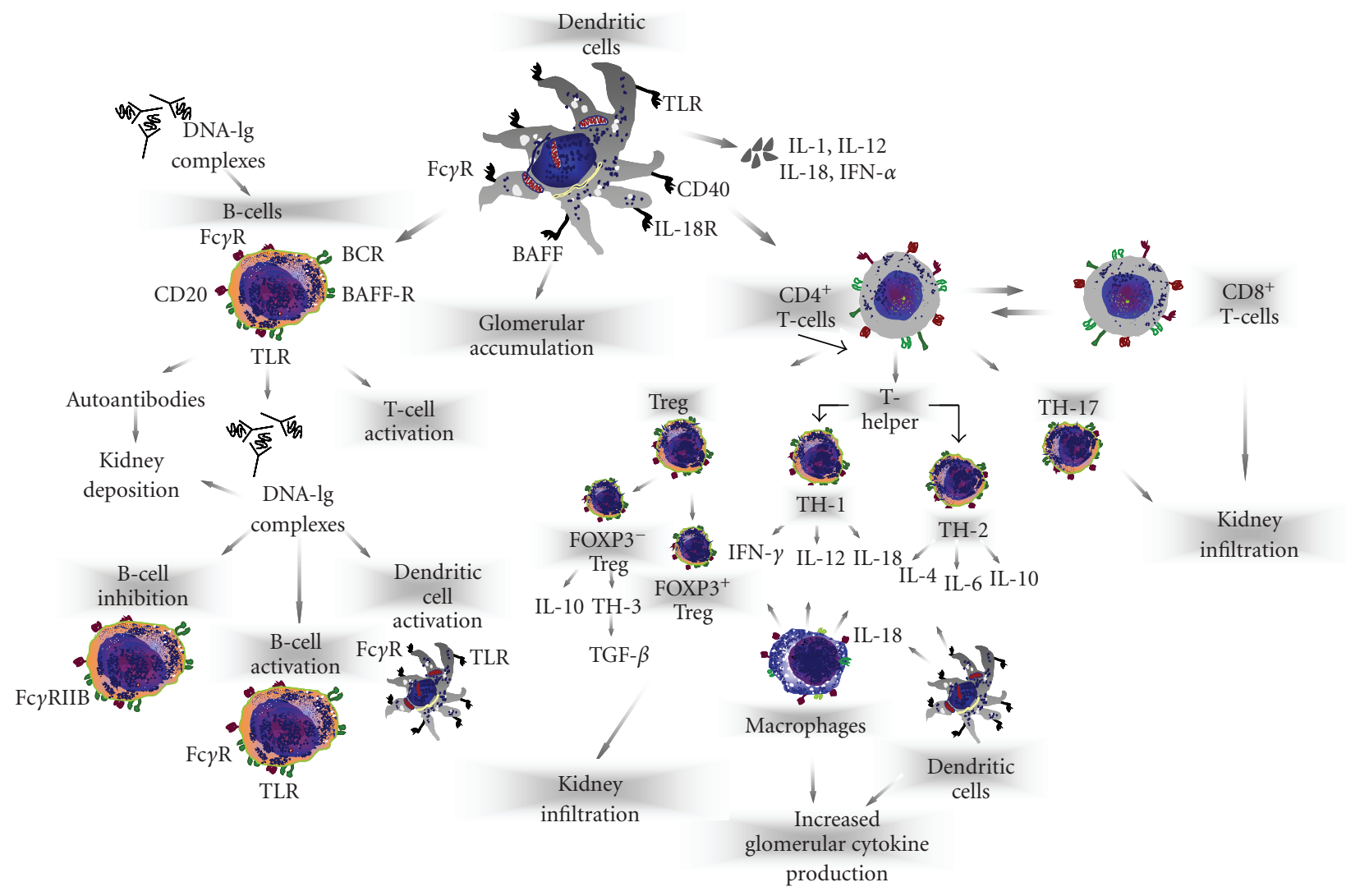

FIGURE 1: Representation of pathogenetic mechanisms of lupus nephritis. LN is a disease that includes several mediators of glomerular inflammation. In this context, T-cell subsets, through the production of nephritogenic cytokines or by cooperating with B-cells, macrophages, and dendritic cells promote the activation of the glomerular immune response.

glomerular IL-18 is nephritogenic since it recruits IL$18 \mathrm{R}^{+} \mathrm{DCs}$, these cells locally produce IL-12, interferon(IFN-) $\gamma$ and CXCR4 thus amplifying the immune-mediated glomerular damage. In addition, expansion of Th-17producing cells and defective number and function of $\mathrm{T}$ regulatory (Treg) cells have been demonstrated in LN [15].

Here, we review recent data on the key role of both Th1 and Th2 cytokines in LN and focus the defect of Th17 and Tregs in the modulation of inflammatory signals leading to the worsening of SLE renal function.

\section{Pathogenetic Relevance of T-Cell Function in Lupus Nephritis}

Derangement of T-cell function has been demonstrated in SLE in parallel to abnormal cytokine production associated to loss of immune tolerance, increased antigenic load, and defective B-cell suppression. A large number of studies suggested that SLE is a Th2-driven disease [5-7]. However, elevation of both Th1 and Th2 cytokines occurs in both humans and mice suggesting that SLE is a complex disease driven by different lymphocyte subsets [8] with high heterogeneity of clinical manifestations and organ involvement (Figure 1).
2.1. T-Cell Activation. T-cells play a crucial role in the pathogenesis of experimental and human LN, since they activate B-cell functions including the production of nephritogenic antibodies and the modulation of $\mathrm{T}$ helper immune response. Moreover, T-cells infiltrate the glomeruli and promote either direct cytotoxicity or recruit other inflammatory cells as macrophages and DCs [16]. Many studies suggested an imbalance in T-cell subsets, and reported an increase of $\mathrm{CD}^{+}$cells with respect to $\mathrm{CD}^{+}$, altered Th1/Th2 cytokine production, and raise of the circulating $\mathrm{CD} 4^{-} / \mathrm{CD} 8^{-}$subset. In this context, murine $\alpha / \beta$ and $\gamma / \delta \mathrm{CD} 4^{-} / \mathrm{CD} 8^{-}$cells induce B-cells to produce both anti-dsDNA and antichromatin antibodies and thus have been considered the major inducer of renal failure in experimental SLE [17-19]. Moreover, disruption of T-cell signals in experimental LN by depletion of $\alpha / \beta$ T-cells or by blocking the CD40/CD40 ligand cascade, delays the inflammatory state of $\mathrm{LN}$ and improves the proteinuria with reduced glomerular accumulation of both inflammatory cells and nephritogenic antibody [20]. In addition, $\gamma / \delta$ T-cells and CD16/CD56 natural killer cells cooperate in lupus, since MLR/lpr mice lacking these populations develop severe nephritis associated with polyclonal $\mathrm{CD}^{+}{ }^{+}$T-cell expansion [21]. Thus, it is conceivable that $\mathrm{CD} 4^{+} \mathrm{T}$-cells exert a negative regulatory function. 
A parallel defective function of T-cell suppressor has been demonstrated. In fact, peripheral $\mathrm{CD} 4^{+} / \mathrm{CD} 25^{+}$Tregs are reduced in patients with active LN, and expansion of this population through tolerogenic peptides strongly delays nephritis as well as the production of auto-antibodies by Bcells [22]. Since T-cell subsets produce different cytokines in response to inflammatory stimuli, their measurement is considered an effective tool for explaining the pathogenetic mechanisms of LN.

2.2. Cytokine Imbalance in Lupus Nephritis. Most of information concerning the pathogenetic role of cytokines in LN derives from murine models relevant for investigating the disease mechanisms under defined experimental conditions. In particular, knock-out mice for either cytokines and/or cytokine-receptors emphasized the role of IFN- $\gamma$ and IL12 [23], since treatment with relative neutralizing antibodies prevents renal disease in NZB/W mice, while IFN- $\gamma$ receptor $^{-/-} \mathrm{MRL} / \mathrm{lpr}$ are protected from glomerulonephritis and show defective anti-dsDNA production [24]. Moreover, these mice strains show high IL-12 production, whereas those defective for the cytokine are protected from LN through inhibition of both IFN- $\gamma$ and IL-18 production. Other studies defined the IL-18 functions in MRL/lpr mice and demonstrated that its glomerular accumulation occurs in patients with proliferative glomerulonephritis and correlates with the infiltration of IL-18R ${ }^{+}$DCs $[8,10,25]$.

However, the majority of therapeutic approaches in humans with biologic or genetic modulation of cytokine production provided inconsistent results. This was at least in part attributed to the identification that IL-23 and IL27 [26], additional members of the IL-6/IL-12 family may amplify the Th1 immune response through expansion of the $\mathrm{CD} 4^{+} \mathrm{Th}^{+} 7^{+}$cells [27]. Th17 cells develop under the influence of IL-6, TGF- $\beta$, and IL-23, and produce IL-17 [28]. Recently, the urinary expression of Th17 related genes has been demonstrated in patients with $\mathrm{LN}$ and thus further studies might be relevant for explaining its role to human LN.

We have recently provided evidence that production of Th1 over Th2 cytokines occurs in active LN, since a defect of both IL- 6 and IL-10 counterbalances elevations of IFN- $\gamma$, IL-12, and IL-18 in both sera and urine in the majority of patients.

IL-6 is a pleyotropic cytokine produced by a large variety of cells that primes the differentiation of B-cells into antibody-producing cells as well as the differentiation of T-cells to effector cells and the activation of macrophages. IL- 6 promotes the proliferation of renal mesangial cells in mice and several studies report IL- 6 as a critical mediator of tissue damage for its ability to stimulate the production of nephritogenic antibodies in humans [29]. Moreover, it has been reported that urinary excretion of IL-6 is elevated in patients with active LN, whereas it declines during the treatment [30]. These studies, however, have not demonstrated a definite relationship between serum and/or urinary IL-6 overproduction in renal disease. As shown in Figure 2(a), we demonstrated in patients with SLE a remarkable increment of serum IL-6 with respect to normal

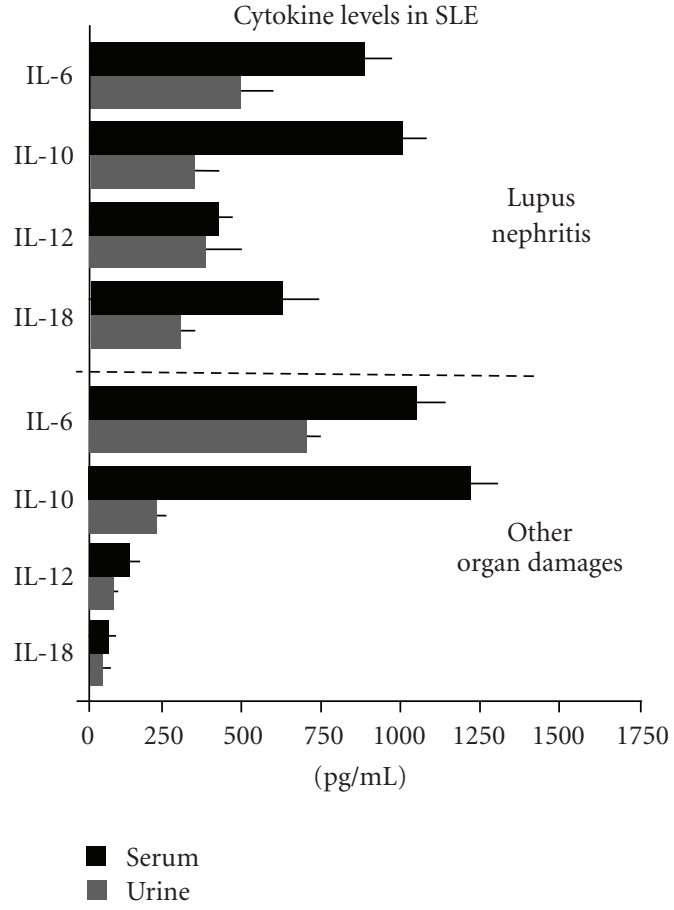

(a)

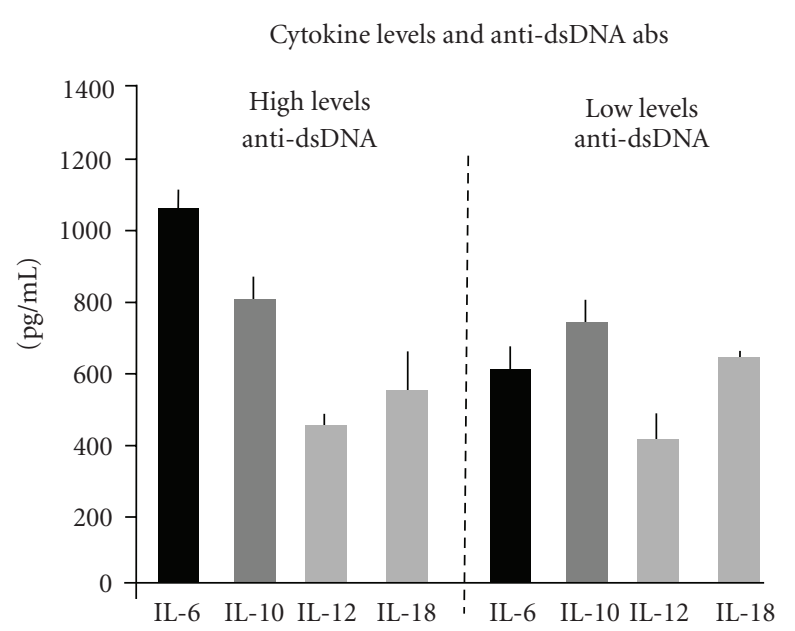

(b)

Figure 2: Th1/Th2 cytokine profile in SLE. (a) Patients with LN $(n=69)$ produced large amounts of both IL-12 and IL-18, both in sera (black column) and urine (gray column). By contrast, those with different organ damages $(n=181)$ excluding LN, showed the highest production of IL-6 and IL-10. (b) IL-6 was overproduced in patients with high levels of anti-dsDNA antibodies independently from the presence of LN. Other cytokines were poorly associated with nephritogenic antibody production.

subjects $(P<.05)$. However, both serum and urinary IL6 levels derived from LN patients were not associated with the presence of renal injury, although they were increased in patients with high levels of anti-dsDNA and antinuclear antibodies (Figure 2(b)). This suggests the potential role of 
IL-6 for the stimulation of auto-antibody production by Bcells, rather than acting as direct mediator of glomerular inflammation.

IL-10 has also been extensively studied. It is a key factor in regulating auto-antibody-secreting B-cell activity and promotes B-cell differentiation [31]. Elevated levels of serum IL-10 occur in SLE, although the treatment with anti-IL-10 monoclonal antibody failed to restore the disease activity in the majority of patients [32]. Moreover, IL-10 elevation occurs in different clinical conditions associated to SLE and a specific association with organ damage has not been definitively elucidated. Our data are in agreement with these results for the high levels of serum IL-10 $(P<.05)$ in both patients with and without LN, whereas elevations of urinary IL-10 were revealed in those with minimal glomerular lesions. Thus, we concluded that overexpression of IL-10 in SLE may reflect an intrinsic defect of the cytokine homeostasis. However, it remains unclear whether elevations of IL-10 are a cause or, rather, an effect of this dysregulation.

Measurement of Th1 cytokines (Figure 2(a)) provided different results, since both IL-12 and IL-18 were strongly overexpressed in LN $(410 \pm 90$ and $618 \pm 105 \mathrm{pg} / \mathrm{ml})$, correlated with IFN- $\gamma$ overproduction $(P<.05)$, and increased in their concentrations within the kidney of patients with proliferative glomerulonephritis. Parallel analyses revealed a large number of $\mathrm{IL}-18 \mathrm{R}^{+} \mathrm{DCs}$ in glomeruli infiltrated by IL- $18^{+}$cells, thus suggesting that the cytokine also exerts a potent chemoattraction of inflammatory cells expressing the functional receptor. Additional studies also demonstrated a peculiar association between both serum and urinary IL-12 with serum IFN- $\gamma(P<.05)$ in LN. In this context, presence of urinary neopterin as a bioactive marker of serum IFN$\gamma$ production further supported the Th1 predominance in kidney inflammation.

\section{Interleukin-17 Producing T-Cells}

IL-17 is a $17-\mathrm{kDa}$ transmembrane protein that includes six members and five receptors mostly produced by activated T-cells. Although the downstream signals activated by IL17R remains to be elucidated, it has been recently shown that its stimulation activates both the nuclear factor $\mathrm{kB}$ and MAP kinase cascades [27]. IL-17 exerts a potent proinflammatory activity in parallel with functional recruitment of macrophages and neutrophils within inflamed tissues through the overproduction of IL- 8 and monocyte chemoattractant protein-1 [33]. This cytokine also allows the expression of adhesion molecules by T-cells as well as the production of IL- 6 and GM-CSF. Lastly, IL-17 synergizes with IL- $1 \beta$, tumor necrosis factor- (TNF-) $\alpha$ and IFN- $\gamma$, and amplifies the Th1 immune response in autoimmune disorders [34].

IL-17 is mostly produced by $\mathrm{CD} 4^{+}, \mathrm{CD}^{+}, \mathrm{CD}^{-} / \mathrm{CD}^{-}$, and $\gamma / \delta$ T-cells, and the $\mathrm{CD}^{+}$T-cell effector subset, namely the Th17 cells, has been distinguished from other $\mathrm{T}$ helper populations for the specific origin, differentiation, and cytokine production. Recent studies demonstrated the involvement of Th17 cell in the pathogenesis of SLE, since $\mathrm{NZB} / \mathrm{NZW}_{\mathrm{F} 1}$ mice produce relevant amounts of the cytokine while IL-17 producing T-cells largely infiltrate the nephritic kidneys of these mice [35]. By contrast, treatment with anti-CD3 monoclonal antibodies delayed the renal damage with concurrent defect of IL-17 production in both serum and glomeruli [36]. Parallel studies in lupus-prone mice described that presence of IL-23 as necessary for the development of a pathogenic Th17 functional immune response. In fact, IL-23 increases the IL-17 production by memory T-cells, thus suggesting a novel T helper functional axis formed by IL23/IL-17 interaction, almost similar to the IL-12/IFN- $\gamma$ system. Moreover, it has been demonstrated that the majority of IL-17 producing T-cells arises from the $\mathrm{CD}^{+} / \mathrm{CD}^{-} / \mathrm{CD}^{-}$subset, that is the typical population revealed in nephritic glomeruli from MRL/lpr mice. Therefore, this cell population is considered an active mediator of renal cytotoxicity $[37,38]$. It is conceivable that $\mathrm{IL}-17^{+} \mathrm{T}$ cells amplify the inflammatory signals activated by other Th1 cytokines. In this context, its inhibition by targeted therapies should represent a novel option for the treatment of patients with overt renal disease.

\section{Regulatory T-Cells and Dendritic Cells in Lupus Nephritis}

Regulatory T-cells (Tregs) are a heterogeneous population of $\mathrm{CD}^{+} / \mathrm{CD}^{+} / \mathrm{CD} 25^{+}$cells differentiated in two subsets in relation to the expression of Foxp 3 transcription factor. The Foxp $3^{-}$population includes both IL-10-producing Tregs and Th3 cells that express the transforming growth factor(TGF-) $\beta$. By contrast, Foxp $3^{+}$Tregs play a protective role in autoimmunity since they regulate the efficiency of the immune response. Notwithstanding Foxp3 is not necessary for the differentiation of Tregs, its expression prevents Tcells to differentiate into Th17 proinflammatory effector Tcells [39]. This is consistent with the accelerated autoimmune manifestations observed in mice depleted of Foxp $3^{+}$Tregs or in humans characterized by a genetic mutation of the Foxp3 gene [40]. Similarly, natural Tregs exert a protective effect in lupus-prone mice, since depletion of $\mathrm{CD} 4^{+} / \mathrm{CD} 25^{+}$cells in $\mathrm{NZB} / \mathrm{NZW} \mathrm{W}_{\mathrm{F} 1}$ accelerates the onset of $\mathrm{LN}$, whereas their transfer into CD4/CD25 knock-out mice delays the glomerulonephritis development. Moreover, high IL-6 production may interfere with Treg function and promote their switch toward Th17-producing cells [41]. In addition, stimulation and activation of DCs in nephritic glomeruli are promoted by interferons while limiting both expansion and protective functions of Tregs in SLE. Thus, although Tregs play an apparent primary role for the homeostasis of the immune system in SLE, the mechanisms leading to their depletion are unclear [42]. It has been suggested that defective number of peripheral Tregs in lupus promotes T- and B-cell hyperactivity while recent studies have attributed this defect to dysfunctional DC activation. For this reason, the restoring of the balance between immunogenic and tolerogenic DCs may represent a mechanism for the inhibition of IL-17 cytotoxicity and the correction of Treg defect during the active phases of LN.

Defective DC function and glomerular accumulation of these cells in LN are regarded as a consequence 
of their increased recruitment from peripheral blood in response to chemotactic stimuli $[10,43]$. DCs interact with renal parenchymal cells through the activation of tolllike-receptors, FC-receptors, c-type lectins, and scavenger receptor, that, once stimulated by either cell-to-cell contact or paracrine signals, accelerate the enrollment of NK, Tcells, and $\gamma / \delta$ lymphocytes in inflammatory sites [44]. Furthermore, DCs exhibit the hallmark of well-equipped antigen-presenting cells in presence of peculiar costimulatory molecules and chemokine profile. In this scenario, presence of DCs within nephritic glomeruli supports their pathogenic effect. This aspect may thus explain why recent therapeutic approaches aimed to their functional disabling, ameliorate nephritis in rodents[45].

\section{Conclusions}

Recent data from experimental and human $\mathrm{LN}$ provided new insights to the role of cytokine interplay in the pathogenesis of renal damage. In this context, a cutting-edge on the Th1 deregulation has been demonstrated and both IL-12 and IL18 exert a major nephritogenic role. However, further studies are needed to clarify the interplay of other mechanisms including both Th17 expansion and defective Treg function within inflamed glomeruli. Therefore, development and progression of renal failure in SLE is an event that involves multiple players whose regulation by novel-therapeutic strategies might prevent the progressive worsening of LN.

\section{References}

[1] D. Koffler, V. Agnello, R. Thoburn, and H. G. Kunkel, "Systemic lupus erythematosus: prototype of immune complex nephritis in man," Journal of Experimental Medicine, vol. 134, no. 3, pp. 169-179, 1971.

[2] C. Scheinecker, B. Zwolfer, M. Koller, G. Manner, and J. S. Smolen, "Alterations of dendritic cells in systemic lupus erythematosus: phenotypic and functional deficiencies," Arthritis and Rheumatism, vol. 44, no. 4, pp. 856-865, 2001.

[3] G. Penna, M. Vulcano, S. Sozzani, and L. Adorini, "Differential migration behavior and chemokine production by myeloid and plasmacytoid dendritic cells," Human Immunology, vol. 63, no. 12, pp. 1164-1171, 2002.

[4] G. Penna, M. Vulcano, A. Roncari, F. Facchetti, S. Sozzani, and L. Adorini, "Cutting edge: differential chemokine production by myeloid and plasmacytoid dendritic cells," Journal of Immunology, vol. 169, no. 12, pp. 6673-6676, 2002.

[5] V. R. Kelley and R. P. Wuthrich, "Cytokines in the pathogenesis of systemic lupus erythematosus," Seminars in Nephrology, vol. 19, no. 1, pp. 57-66, 1999.

[6] M. Funauchi, S. Ikoma, H. Enomoto, and A. Horiuchi, "Decreased Th1-like and increased Th2-like cells in systemic lupus erythematosus," Scandinavian Journal of Rheumatology, vol. 27, no. 3, pp. 219-224, 1998.

[7] M. Akahoshi, H. Nakashima, Y. Tanaka, et al., "Th1/Th2 balance of peripheral T helper cells in systemic lupus erythematosus," Arthritis and Rheumatism, vol. 42, no. 8, pp. 1644$1648,1999$.

[8] J. T. Chang, B. M. Segal, K. Nakanishi, H. Okamura, and E. M. Shevach, "The costimulatory effect of IL-18 on the induction of antigen-specific IFN- $\gamma$ production by resting T cells is IL12 dependent and is mediated by up-regulation of the IL-12 receptor $\beta 2$ subunit," European Journal of Immunology, vol. 30, no. 4, pp. 1113-1119, 2000.

[9] E. Esfandiari, I. B. McInnes, G. Lindop, et al., "A proinflammatory role of IL-18 in the development of spontaneous autoimmune disease," Journal of Immunology, vol. 167, no. 9, pp. 5338-5347, 2001.

[10] M. Tucci, C. Quatraro, L. Lombardi, C. Pellegrino, F. Dammacco, and F. Silvestris, "Glomerular accumulation of plasmacytoid dendritic cells in active lupus nephritis: Role of interleukin-18," Arthritis and Rheumatism, vol. 58, no. 1, pp. 251-262, 2008.

[11] M. Tucci, L. Lombardi, H. B. Richards, F. Dammacco, and F. Silvestris, "Overexpression of interleukin-12 and T helper 1 predominance in lupus nephritis," Clinical and Experimental Immunology, vol. 154, no. 2, pp. 247-254, 2008.

[12] M. Linker-Israeli, R. J. Deans, D. J. Wallace, J. Prehn, T. OzeriChen, and J. R. Klinenberg, "Elevated levels of endogenous IL-6 in systemic lupus erythematosus: a putative role in pathogenesis," Journal of Immunology, vol. 147, no. 1, pp. 117$123,1991$.

[13] J. C. Crispin and J. Alcocer-Varela, "The role myeloid dendritic cells play in the pathogenesis of systemic lupus erythematosus," Autoimmunity Reviews, vol. 6, no. 7, pp. 450-456, 2007.

[14] M. Tucci, S. Ciavarella, S. Strippoli, F. Dammacco, and F. Silvestris, "Oversecretion of cytokines and chemokines in lupus nephritis is regulated by intraparenchymal dendritic cells: a review," Annals of the New York Academy of Sciences, vol. 1173, pp. 449-457, 2009.

[15] M. Oukka, "Interplay between pathogenic Th17 and regulatory T cells," Annals of the Rheumatic Diseases, vol. 66, supplement 3, pp. iii87-iii90, 2007.

[16] V. C. Kyttaris and G. C. Tsokos, "T lymphocytes in systemic lupus erythematosus: an update," Current Opinion in Rheumatology, vol. 16, no. 5, pp. 548-552, 2004.

[17] A. N. Theofilopoulos, G. J. Prud'Homme, and F. J. Dixon, "Autoimmune aspects of systemic lupus erythematosus," Concepts in Immunopathology, vol. 1, pp. 190-218, 1985.

[18] A. N. Theofilopoulos and F. J. Dixon, "Murine models of systemic lupus erythematosus," Advances in Immunology, vol. 37, pp. 269-390, 1985.

[19] J. A. Kapp, L. M. Kapp, and K. C. McKenna, " $\gamma \Delta$ T cells play an essential role in several forms of tolerance," Immunologic Research, vol. 29, no. 1-3, pp. 93-102, 2004.

[20] D. I. Daikh, B. K. Finck, P. S. Linsley, D. Hollenbaugh, and D. Wofsy, "Long-term inhibition of murine lupus by brief simultaneous blockade of the B7/CD28 and CD40/gp39 costimulation pathways," Journal of Immunology, vol. 159, no. 7, pp. 3104-3108, 1997.

[21] T. Wada, A. Schwarting, M. S. Chesnutt, D. Wofsy, and V. R. Kelly, "Nephritogenic cytokines and disease in MRL-Fas $s^{l p r}$ kidneys are dependent on multiple T-cell subsets," Kidney International, vol. 59, no. 2, pp. 565-578, 2001.

[22] M.-F. Liu, C.-R. Wang, L.-L. Fung, and C.-R. Wu, "Decreased $\mathrm{CD} 4^{+} \mathrm{CD} 25^{+} \mathrm{T}$ cells in peripheral blood of patients with systemic lupus erythematosus," Scandinavian Journal of Immunology, vol. 59, no. 2, pp. 198-202, 2004.

[23] X. Fan, B. Oertli, and R. P. Wuthrich, "Up-regulation of tubular epithelial interleukin-12 in autoimmune MRL-Fas ${ }^{l p r}$ mice with renal injury," Kidney International, vol. 51, no. 1, pp. 79-86, 1997.

[24] E. Kikawada, D. M. Lenda, and V. R. Kelley, "IL-12 deficiency in MRL-Fas ${ }^{l p r}$ mice delays nephritis and intrarenal IFN- $\gamma$ 
expression, and diminishes systemic pathology," Journal of Immunology, vol. 170, no. 7, pp. 3915-3925, 2003.

[25] A. Kaser, S. Kaser, N. C. Kaneider, B. Enrich, C. J. Wiedermann, and H. Tilg, "Interleukin-18 attracts plasmacytoid dendritic cells (DC2s) and promotes Th1 induction by DC2s through IL-18 receptor expression," Blood, vol. 103, no. 2, pp. 648-655, 2004.

[26] B. Oppmann, R. Lesley, B. Blom, et al., "Novel p19 protein engages IL-12p40 to form a cytokine, IL-23, with biological activities similar as well as distinct from IL-12," Immunity, vol. 13, no. 5, pp. 715-725, 2000.

[27] T. Korn, E. Bettelli, M. Oukka, and V. K. Kuchroo, "IL-17 and Th17 cells," Annual Review of Immunology, vol. 27, pp. 485517, 2009.

[28] A. Awasthi, L. Riol-Blanco, A. Jager, et al., "Cutting edge: IL-23 receptor gfp reporter mice reveal distinct populations of IL17-producing cells," The Journal of Immunology, vol. 182, pp. 5904-5908, 2009.

[29] H. B. Richards, M. Satoh, M. Shaw, C. Libert, V. Poli, and W. H. Reeves, "Interleukin 6 dependence of anti-DNA antibody production: evidence for two pathways of autoantibody formation in pristane-induced lupus," Journal of Experimental Medicine, vol. 188, no. 5, pp. 985-990, 1998.

[30] M. Iwano, K. Dohi, E. Hirata, et al., "Urinary levels of IL-6 in patients with active lupus nephritis," Clinical Nephrology, vol. 40, no. 1, pp. 16-21, 1993.

[31] Y. B. Park, S. K. Lee, D. S. Kim, J. Lee, C. H. Lee, and C. H. Song, "Elevated interleukin-10 levels correlated with disease activity in systemic lupus erythematosus," Clinical and Experimental Rheumatology, vol. 16, no. 3, pp. 283-288, 1998.

[32] S. M. Proudman, P. G. Conaghan, C. Richardson, et al., "Clinical and biologic effects of anti-interleukin-10 monoclonal antibody administration in systemic Lupus erythematosus," Arthritis and Rheumatism, vol. 43, no. 8, pp. 1790-1800, 2000.

[33] S. Agarwal, R. Misra, and A. Aggarwal, "Synovial fluid RANKL and matrix metalloproteinase levels in enthesitis related arthritis subtype of juvenile idiopathic arthritis," Rheumatology International, vol. 29, no. 8, pp. 907-911, 2009.

[34] S. Aggarwal, N. Ghilardi, M.-H. Xie, F. J. de Sauvage, and A. L. Gurney, "Interleukin-23 promotes a distinct CD4 $\mathrm{T}$ cell activation state characterized by the production of interleukin-17," Journal of Biological Chemistry, vol. 278, no. 3, pp. 1910-1914, 2003.

[35] S. D. Fleming, M. Monestier, and G. C. Tsokos, "Accelerated ischemia/reperfusion-induced injury in autoimmunity-prone mice," Journal of Immunology, vol. 173, no. 6, pp. 4230-4235, 2004.

[36] H. Y. Wu, F. J. Quintana, and H. L. Weiner, "Nasal antiCD3 antibody ameliorates lupus by inducing an IL-10secreting $\mathrm{CD}^{+} \mathrm{CD} 25^{-} \mathrm{LAP}^{+}$regulatory $\mathrm{T}$ Cell and is associated with down-regulation of $\mathrm{IL}_{-} 17^{+} \mathrm{CD} 4^{+} \mathrm{ICOS}^{+} \mathrm{CXCR}^{+}$ follicular helper T cells," Journal of Immunology, vol. 181, no. 9, pp. 6038-6050, 2008.

[37] Y. Wang, S. Ito, Y. Chino, et al., "Use of laser microdissection in the analysis of renal-infiltrating T cells in MRL/lpr mice," Modern Rheumatology, vol. 18, no. 4, pp. 385-393, 2008.

[38] Y. Wang, S. Ito, Y. Chino, et al., "Laser microdissection-based analysis of cytokine balance in the kidneys of patients with lupus nephritis," Clinical and Experimental Immunology, vol. 159, no. 1, pp. 1-10, 2010.

[39] D. A. Horwitz, "Regulatory T cells in systemic lupus erythematosus: past, present and future," Arthritis Research and Therapy, vol. 10, no. 6, 2008.
[40] D. A. Horwitz, S. G. Zheng, and J. D. Gray, "Natural and TGF- $\beta$-induced Foxp $3{ }^{+} \mathrm{CD} 4{ }^{+} \mathrm{CD} 25^{+}$regulatory T cells are not mirror images of each other," Trends in Immunology, vol. 29, no. 9, pp. 429-435, 2008.

[41] S. G. Zheng, J. Wang, and D. A. Horwitz, "Cutting edge: Foxp $3^{+} \mathrm{CD}^{+} \mathrm{CD}^{2} 5^{+}$regulatory $\mathrm{T}$ cells induced by IL-2 and TGF- $\beta$ are resistant to Th17 conversion by IL-6," Journal of Immunology, vol. 180, no. 11, pp. 7112-7116, 2008.

[42] G. Filaci, S. Bacilieri, M. Fravega, et al., "Impairment of CD8 ${ }^{+}$ $\mathrm{T}$ suppressor cell function in patients with active systemic lupus erythematosus," Journal of Immunology, vol. 166, no. 10, pp. 6452-6457, 2001.

[43] N. Fiore, G. Castellano, A. Blasi, et al., "Immature myeloid and plasmacytoid dendritic cells infiltrate renal tubulointerstitium in patients with lupus nephritis," Molecular Immunology, vol. 45, no. 1, pp. 259-265, 2008.

[44] A. Iwasaki and R. Medzhitov, "Toll-like receptor control of the adaptive immune responses," Nature Immunology, vol. 5, no. 10, pp. 987-995, 2004.

[45] N. M. Rogers, T. J. Matthews, J. Y. Kausman, R. A. Kitching, and P. T. H. Coates, "Review article: kidney dendritic cells: their role in homeostasis, inflammation and transplantation," Nephrology, vol. 14, no. 7, pp. 625-635, 2009. 


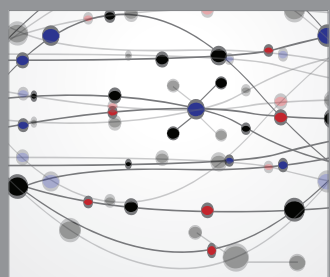

The Scientific World Journal
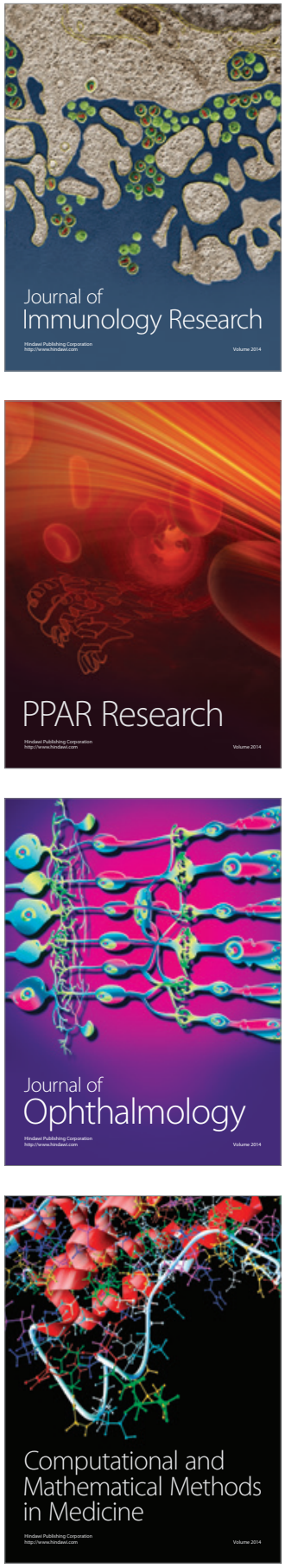

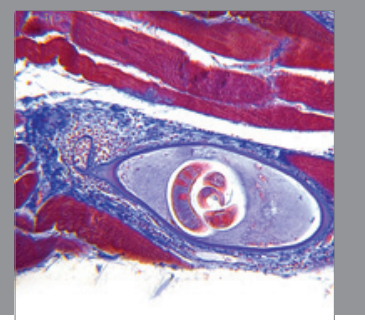

Gastroenterology

Research and Practice
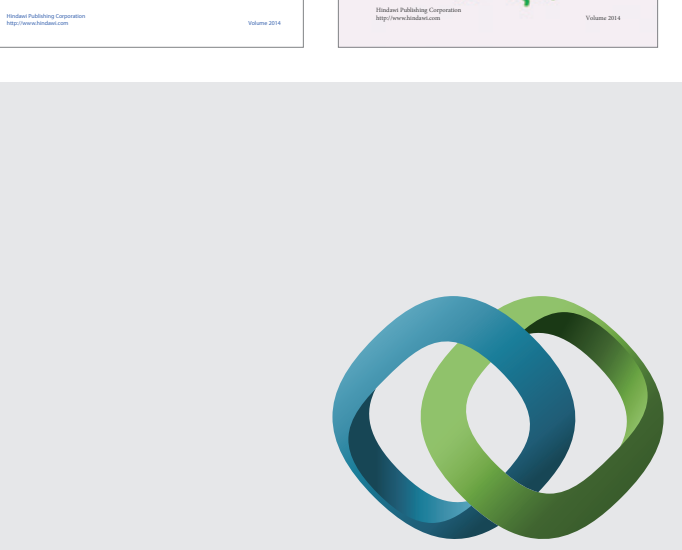

\section{Hindawi}

Submit your manuscripts at

http://www.hindawi.com
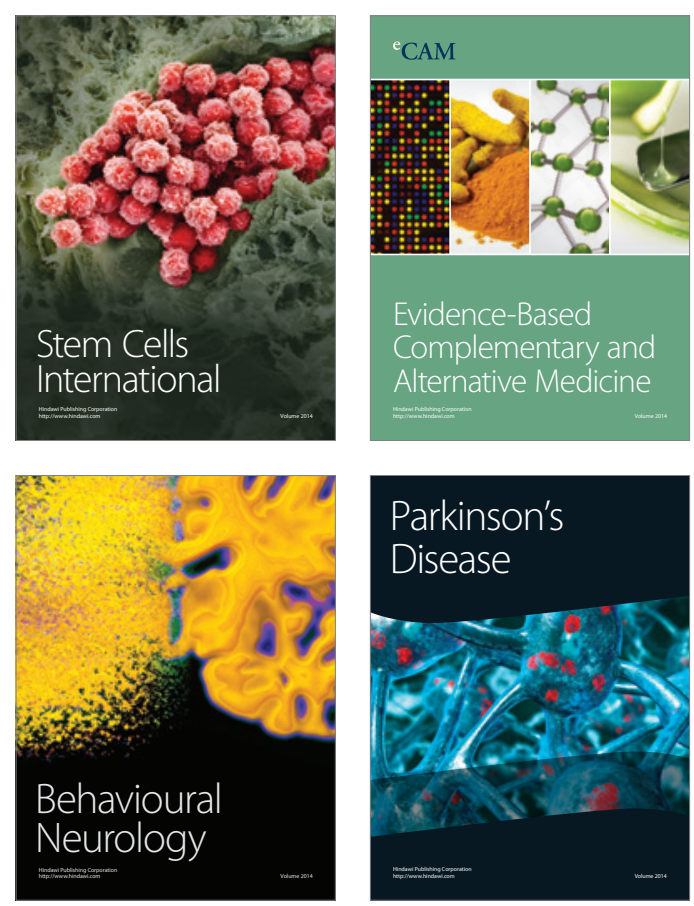

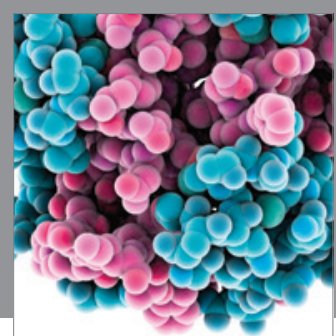

Journal of
Diabetes Research

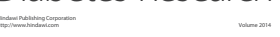

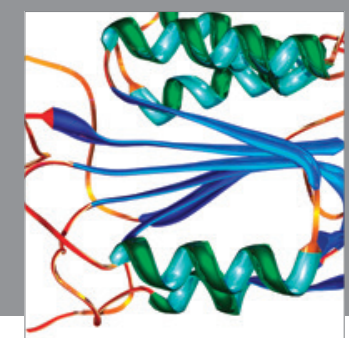

Disease Markers
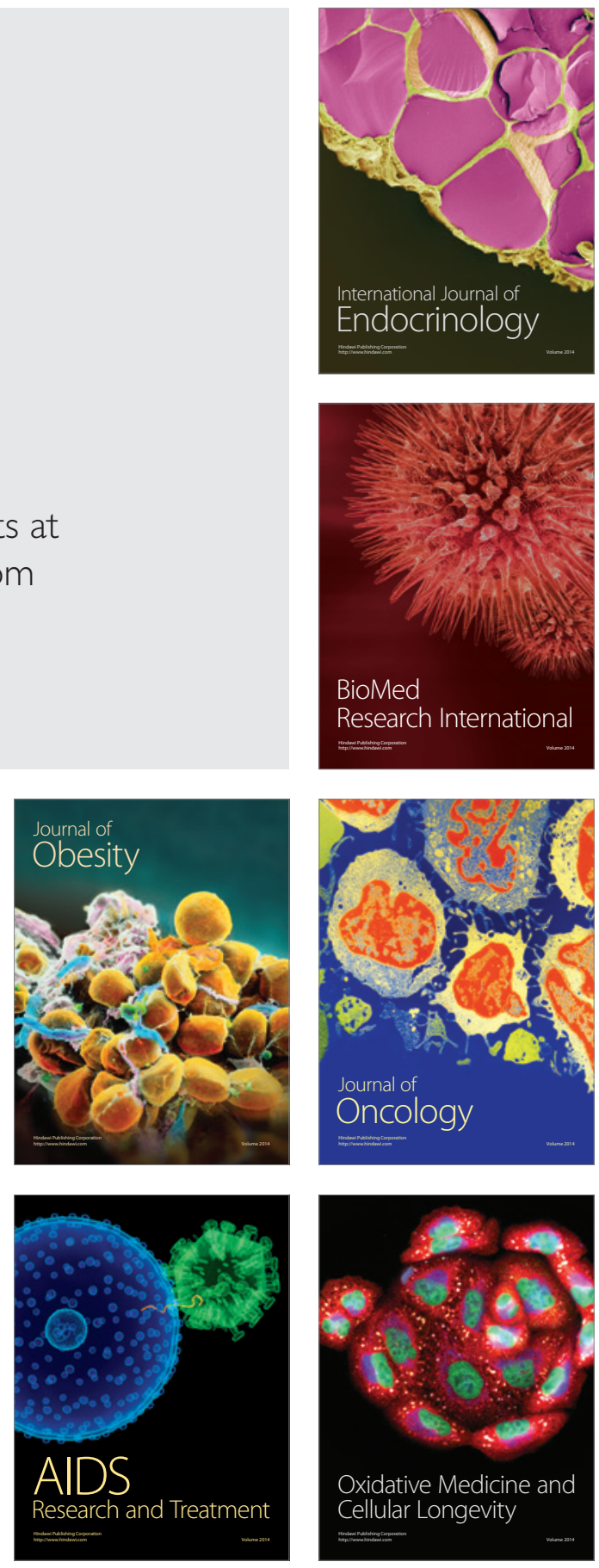